\title{
Michigan Ophthalmology Pipeline: Exploring a Mentorship Model to Increase Diversity in Ophthalmology
}

\author{
Mason A. Shaner, BS ${ }^{1}$ Ariane Kaplan, MD ${ }^{1,2}$ Christopher Sesi, BS ${ }^{1}$ Abhishek Manjunathan, BBA ${ }^{1}$ \\ Gabrielle D. Lacy, BS ${ }^{1}$ Lauren Prisk, BA ${ }^{1,2}$ Jara Crear, MD ${ }^{1,2}$ Alan Sugar, MD ${ }^{1,2}$ Angela Elam, MD ${ }^{1,2}$ \\ Shahzad I. Mian, MD ${ }^{1,2}$
} 1 University of Michigan Medical School, Ann Arbor, Michigan
${ }^{2}$ Department of Ophthalmology and Visual Sciences, Kellogg Eye
Center, Michigan Medicine, Ann Arbor, Michigan
Address for correspondence Shahzad I. Mian, MD, Department of Ophthalmology and Visual Sciences 1000 Wall Street, Ann Arbor, MI 48105 (e-mail: smian@med.umich.edu).

J Acad Ophthalmol 2020;12:e1-e7.

\begin{abstract}
Keywords

- diversity in ophthalmology

- mentorship

- underrepresented minorities in medicine

- pipeline program

Background Ethnic concordance between physicians and patients improves compliance and therapeutic benefit. Current literature shows a lack of diversity within ophthalmology. Thus, we aimed to develop a longitudinal mentorship program between first year ophthalmology residents (PGY2s) and first year medical students (M1s) coming from minority communities underrepresented in medicine (URM) to provide early exposure to the field.

Methods M1 members of URM organizations were recruited and paired with PGY2 ophthalmology residents in a mentorship program between 2017 and 2019. All participants were surveyed twice annually.

Results All 2017 M1s stated increased interest in ophthalmology, felt "satisfied" or "very satisfied" with the program, and completed all requirements. At the year-end, the mean educational value of the program for $2017 \mathrm{M} 1 \mathrm{~s}$ was rated $4.33 / 5$, and interest in ophthalmology 4.67/5. Quality of the clinical experiences for 2017 PGY2s 3.5/5, and the overall effectiveness of the program 3.5/5. At the year-end, the average educational value of the program for $2018 \mathrm{M} 1 \mathrm{~s}$ was $4.4 / 5$, and interest in ophthalmology 4.0/5. Quality of the clinical experiences for 2018 PGY2s was 3.1/5, and the overall effectiveness of the program was 3.4/5.

Conclusion Our "pipeline" program represents an ongoing effort to increase URM interest in ophthalmology. Continued assessment to identify areas for growth and improvement can optimize the program to aid other programs in initiating efforts to tackle this important issue.
\end{abstract}

Studies demonstrate that ethnic concordance between physician and patient improves patient compliance and therapeutic benefit. ${ }^{1}$ Ophthalmology remains a specialty of low diversity. An optimal, population-based strategy for the future treatment of ophthalmologic disease includes increasing the number of practicing ophthalmologists who come from underrepresented

received

August 27, 2019 accepted after revision November 18, 2019
DOI https://doi.org/

10.1055/s-0039-3402074. ISSN 2475-4757. backgrounds. Currently, $6 \%$ of practicing ophthalmologists and 7.7\% of ophthalmology residents identify as coming from minority communities underrepresented in medicine (URM), while the prevalence of these minorities in the United States is approximately $30 \%^{2,3}$ In some areas, this difference is even larger. ${ }^{4}$
Copyright $\odot 2020$ by Thieme Medical Publishers, Inc., 333 Seventh Avenue, New York, NY 10001, USA. Tel: +1(212) 584-4662.
License terms

(요 (1) $\Theta$ 
Lack of ophthalmologists in underserved communities, financial disparities and patient mistrust of physicians present significant barriers to care. These barriers are reduced when physician and patient come from similar ethnic backgrounds, with patients reporting greater satisfaction with communication and treatment outcomes when they receive care from physicians of the same race/ethnicity. ${ }^{5-9}$ URM physicians return frequently to underserved communities, including areas which traditionally lack ophthalmologists. ${ }^{8}$ Efforts aimed at diversifying the ophthalmology workforce address the sense of alienation experienced by patients who have difficulty relating to physicians of a background different from their own. While such a project may take time, early intervention is important. By 2050, the prevalence of common ophthalmologic diseases is predicted to double, increasing the demand for diversity in ophthalmologists. ${ }^{10}$

Many barriers deter medical students from pursuing careers in ophthalmology, including its competitiveness, lack of student exposure to ophthalmology, and lack of time for career exploration beyond the required core clerkships within the medical curriculum. URM students face additional challenges including limited familial, financial, or educational support and encouragement. ${ }^{11}$ The University of Michigan Medical School (UMMS), Doctors of Tomorrow (DoT) program addresses similar barriers at the secondary level with a mentorship-based model. This model pairs high school students from underrepresented minorities with medical student mentors who act as point persons to help increase exposure to medicine and provide educational and social support. DoT has been successful, with two former students now attending medical school and 18 former students pursuing their undergraduate education at the University of Michigan. ${ }^{12}$

Inspired by the success DoT has achieved, we created the Michigan Ophthalmology Pipeline (MOP) program. This pilot program seeks to facilitate longitudinal mentorship between ophthalmology residents at the Kellogg Eye Center (KEC) and URM medical students, with the aim of increasing diversity within ophthalmology. MOP is predicated on the hypothesis that forming these near-peer relationships at the institutional level will provide medical students a support structure with which to navigate medical school and ultimately inspire URM students to pursue a career in ophthalmology. From a resident perspective, this program aims to enhance their training as future leaders and educators in the field. This paper discusses the successes and challenges encountered over the first 2 years of the program.

\section{Methods}

\section{Recruitment}

Incoming URM first year medical students (M1s) were paired with first year ophthalmology residents (PGY2s) as opposed to pairing students with faculty, to leverage the mentorship opportunities that come with near-peer relationships. Recruitment efforts began within the first months of medical school when students have little exposure to ophthalmology and are in the early stages of forming their professional identity.
MOP partners with two prominent URM organizations at the medical school: the Black Medical Association (BMA) and the Latin American and Native American Medical Association (LANAMA), to aid in recruiting efforts. Interested M1s attended a dinner meeting with their prospective PGY2 mentors, ophthalmology faculty, and leadership to learn more about the program, after which an application was released. All interested M1s were welcomed to apply, regardless of URM status.

\section{Program Design}

The program is designed to facilitate a mentoring relationship for the duration of medical school, while also providing supplemental educational experiences. As students' progress through medical school, they maintain their relationship with residents, who continue their leadership roles as PGY3s and PGY4s. The aspects of the program can be divided into the following components:

Educational events and skill building: the program hosts several clinical skills nights, where resident mentors introduce the basics of clinical ophthalmology, including ocular anatomy, direct and indirect ophthalmoscopy, and slit-lamp techniques. The students also participate in a surgical simulation experience with a cataract simulator (VRmagic, Mannheim, Germany) to practice basic microsurgery techniques. Various suturing and knot-tying skills events are held to further develop students' surgical skills and interest. Participants also have the opportunity to participate in healthcare disparity journal club events with the UMMS ophthalmology student interest group.

Mentor-guided clinical immersion: students attend ophthalmology clinics or observe surgery at least thrice per semester and work on the ophthalmology inpatient consult or night-float service at least once per semester. These experiences utilize the mentor-mentee relationship to create an inviting learning environment, while serving as an opportunity for mentors to develop as educators.

Global networking: the ophthalmology department hosts a visiting professorship to discuss health care disparities in ophthalmology. Mentors and mentees meet with the visiting professor in a separate event to provide an opportunity for them to interact with a national leader in the field.

Research opportunities: mentees are connected with numerous research opportunities focused on diversity, equity, and inclusion (DEI) efforts. The Health Equity Ophthalmology Student Program is an affiliated program that provides two students between their M1 and M2 years with combined research and clinical funding. Those students have the opportunity to submit their work for presentation at national conferences, giving them an opportunity to further network with leaders in ophthalmology. In addition, the program hosts a DEI weekend every year to engage all members of the community. Six out of 28 residents and 2 out of 121 faculty identify as URM, but students have reported no difficulty in finding mentors who share their passion for diversity efforts at our institution.

Community building: in an effort to build community, MOP hosts numerous potluck meals and social events, such as bowling, throughout the year. Many mentees cite this as a way to form stronger relationships with their mentors outside of the clinical environment. 


\section{Evaluation}

Mentee and mentor feedback provides insight into how the program is meeting the needs of its participants. M1s and PGY2s are surveyed anonymously twice annually. Question phrasing can be found in - Appendix Tables 1-3. The surveys are designed to gather information regarding the quality of clinical experiences, program value and satisfaction, and suggestions for improvement.

\section{Results}

The program was first implemented during the 2017 to 2018 academic year. Nine medical students applied for and joined the program, five of whom identify as URM, and all seven of KEC's PGY2s served as mentors. In the second year, twelve M1s applied for seven mentee positions in fall 2018. All seven selected mentees identified as URM and all newly entering PGY2s in 2018 participated. All nine M2s and seven PGY3s from the 2017 cohort have continued in the program.

Midyear and year-end feedback collected from the 2017 cohort showed mentees and mentors both had a positive response to the program (-Table 1 ). Several students shared the sentiment "I have maintained my interest in ophthalmology, and this experience has made it even stronger!" The year-end feedback continued the following positive trend: all M1s stated that interest in ophthalmology increased since beginning the program, and PGY2s identified the program as a means to connect with students from different backgrounds and an opportunity to gain educator experience. All M1s would recommend the program to other students and all responding PGY2s would recommend that future residents participate in the program.

Midyear feedback collected from mentees and mentors in the 2018 cohort was less positive than the previous year (-Table 1). Not all mentees were able to complete shadowing requirements ( $\mathbf{-}$ Table $\mathbf{2}$ ). Mentees stated that the program provided opportunities to learn more about ophthalmology and felt comfortable asking questions. Mentee suggestions for improvement included additional social time to connect with mentors on a personal level, less stringent shadowing requirements, and additional information about ophthal-

Table 1 Midyear feedback responses

\begin{tabular}{|c|c|c|c|}
\hline Question & $\begin{array}{l}2017 \\
(n=9)\end{array}$ & $\begin{array}{l}2018 \\
(n=7)\end{array}$ & $p$-Value \\
\hline $\begin{array}{l}\text { Mentee: education } \\
\text { value (mean) }{ }^{\mathrm{a}}\end{array}$ & 4.22 & 3.71 & 0.62 \\
\hline $\begin{array}{l}\text { Mentor: clinical experience } \\
\text { satisfaction (mean) }^{\mathrm{a}}\end{array}$ & 4.8 & 3.14 & 0.10 \\
\hline $\begin{array}{l}\text { Mentee: increased } \\
\text { ophthalmology interest }^{\mathrm{b}}\end{array}$ & $89 \%$ & $43 \%$ & 0.06 \\
\hline $\begin{array}{l}\text { Mentee: satisfaction } \\
\text { with programb }\end{array}$ & $100 \%$ & $71 \%$ & 0.09 \\
\hline
\end{tabular}

Note: comparison of midyear anonymous feedback responses from 2017 and 2018 cohorts.

${ }^{\mathrm{a}}$ Responses were on a scale from 1 to 5 in increasing value.

bercentage of "yes" responses.
Table 2 Percentage of mentees who completed year-end requirements

\begin{tabular}{|l|l|l|l|}
\hline Requirement & $\begin{array}{l}2017 \\
(n=6)\end{array}$ & $\begin{array}{l}2018 \\
(n=5)\end{array}$ & $p$-Value \\
\hline $\begin{array}{l}\geq 3 \text { clinical experiences } \\
\text { (operating room and/or clinic) }\end{array}$ & $100 \%$ & $60 \%$ & 0.10 \\
\hline$\geq 1$ consult/call experience & $66.67 \%$ & $80 \%$ & 0.64 \\
\hline
\end{tabular}

Note: Mentees attend clinic and/or observe surgery at least three times per semester and work on the ophthalmology inpatient consult or nightfloat service at least once per semester with their mentor.

mology in practice. Mentor suggestions for improvement included administrative support in scheduling clinical and surgical experiences with mentees, fewer required mentee experiences, resident participation be optional, and social events better accommodate resident schedules. The year-end feedback from the 2018 cohort demonstrated improvement from the midyear feedback, and overall, the 2018 year-end results were just slightly less positive than those of the 2017 cohort. - Tables 3 and 4 summarize 2017 and 2018 mentee and mentor year-end responses, respectively.

-Figs. 1-3 further break down the differences in responses between the two cohorts at the midyear and year-end for mentee perceived educational value, mentee satisfaction, and mentor perceived quality of clinical experience with their mentee.

\section{Discussion}

In an attempt to promote diversity within ophthalmology, we created a longitudinal mentorship program to increase interest among URM medical students in the field. The pilot program has been successful, with two cohorts currently enrolled. Many students credit the program for increasing their interest in ophthalmology, citing the close relationships they have made with residents, and the educational opportunities available to them. Residents appreciated the

Table 3 Mentee year-end feedback responses on a scale from 1 to 5 with increasing value

\begin{tabular}{|c|c|c|c|}
\hline Question & $\begin{array}{l}2017 \\
(n=6)\end{array}$ & $\begin{array}{l}2018 \\
(n=5)\end{array}$ & $p$-Value \\
\hline Educational value & 4.33 & 4.4 & 0.95 \\
\hline $\begin{array}{l}\text { Increased ophthalmology } \\
\text { interest }\end{array}$ & 4.67 & 4.0 & 0.53 \\
\hline $\begin{array}{l}\text { Improved ophthalmology } \\
\text { knowledge }\end{array}$ & 5 & 4.4 & 0.41 \\
\hline $\begin{array}{l}\text { Increased knowledge of } \\
\text { ophthalmology DEl efforts }\end{array}$ & 4.5 & 4.2 & 0.78 \\
\hline $\begin{array}{l}\text { Confidence in } \\
\text { ophthalmological } \\
\text { clinical skills }\end{array}$ & 3.67 & 3.0 & 0.65 \\
\hline
\end{tabular}

Abbreviation: DEI, diversity, equity, and inclusion.

Note: comparison of mentee year-end anonymous feedback responses from 2017 and 2018 cohorts. 
e4 A Mentorship Model to Increase Diversity in Ophthalmology Shaner et al.

Table 4 Mentor year-end feedback responses on a scale of 1 to 5 with increasing value

\begin{tabular}{|l|l|l|l|}
\hline Question & $\begin{array}{l}\mathbf{2 0 1 7} \\
(\boldsymbol{n}=\mathbf{4})\end{array}$ & $\begin{array}{l}\mathbf{2 0 1 8} \\
(\boldsymbol{n}=\mathbf{5})\end{array}$ & $p$-Value \\
\hline $\begin{array}{l}\text { Quality of clinical } \\
\text { experience with mentee }\end{array}$ & 3.5 & 3.1 & 0.81 \\
\hline Growth as an educator & 3.5 & 3.4 & 0.95 \\
\hline $\begin{array}{l}\text { Increased knowledge of } \\
\text { ophthalmology DEl efforts }\end{array}$ & 3.5 & 3.6 & 0.95 \\
\hline Effectiveness of program & 3.5 & 3.4 & 0.95 \\
\hline
\end{tabular}

Note: comparison of mentor year-end anonymous feedback responses from 2017 and 2018 cohorts.

Abbreviation: DEI, diversity, equity, and inclusion.

opportunity to enhance their teaching skills and work as mentors to URM students.

Other programs have addressed diversity in medical subspecialties by engaging URM medical students. The Johns Hopkins Dermatology Department created a dermatology outreach program for minority high school students in the Baltimore area and partnered with a medical student organization supporting URM students to host events throughout the year. ${ }^{13}$ Northwestern Feinberg School of Medicine offers a pipeline program that pairs URM medical students with resident mentors in their desired specialty. ${ }^{14}$ The American Academy of Orthopaedic Surgeons developed a mentorship program in which URM and female medical students are paired with a faculty mentor in orthopaedic surgery. ${ }^{15}$ The UMMS has made a concerted effort to increase the diversity of the student body, with the most recent M1 class consisting of $20 \%$ URM and $65 \%$ female students. Next steps include increasing diversity among faculty to provide better mentorship to these students and residents.

Within ophthalmology, the American Academy of Ophthalmology (AAO) and the Association of University Professors of Ophthalmology (AUPO) developed the Minority Ophthalmology Mentoring (MOM) program that operates at a national level to connect URM M1s and M2s with a mentor ophthalmologist. ${ }^{16}$ Through assistance with board examination preparation, career guidance, and bringing students and mentors together during a "Student Engagement Weekend," the AAO and AUPO help interested URM students to attain their goal of becoming an ophthalmologist. MOP builds on these successes by connecting students with residents at the institutional level and leveraging the near-peer nature of their relationship for consistent mentorship throughout medical school. These core mentor-mentee pairings are supplemented with a faculty presence to make research more accessible. By providing resources and encouragement to build competitive residency applications, we hope that the program will embolden more URM students to pursue a career in ophthalmology.

During the more recent year, the program has received variable feedback and barriers have been illuminated highlighting areas for improvement. Although survey responses were not statistically different significantly due to the small sample sizes, the second cohort's feedback was qualitatively less positive. Overall, the first cohort of students and residents viewed their participation in the program as a positive experience, while midyear survey results from the second cohort demonstrated lower satisfaction ratings and fewer mentees

\section{Mentee satisfaction}

$\square$ Very unsatisfied Unsatisfied $\square$ Neutral $\square$ Satsified $\square$ Very satisfied

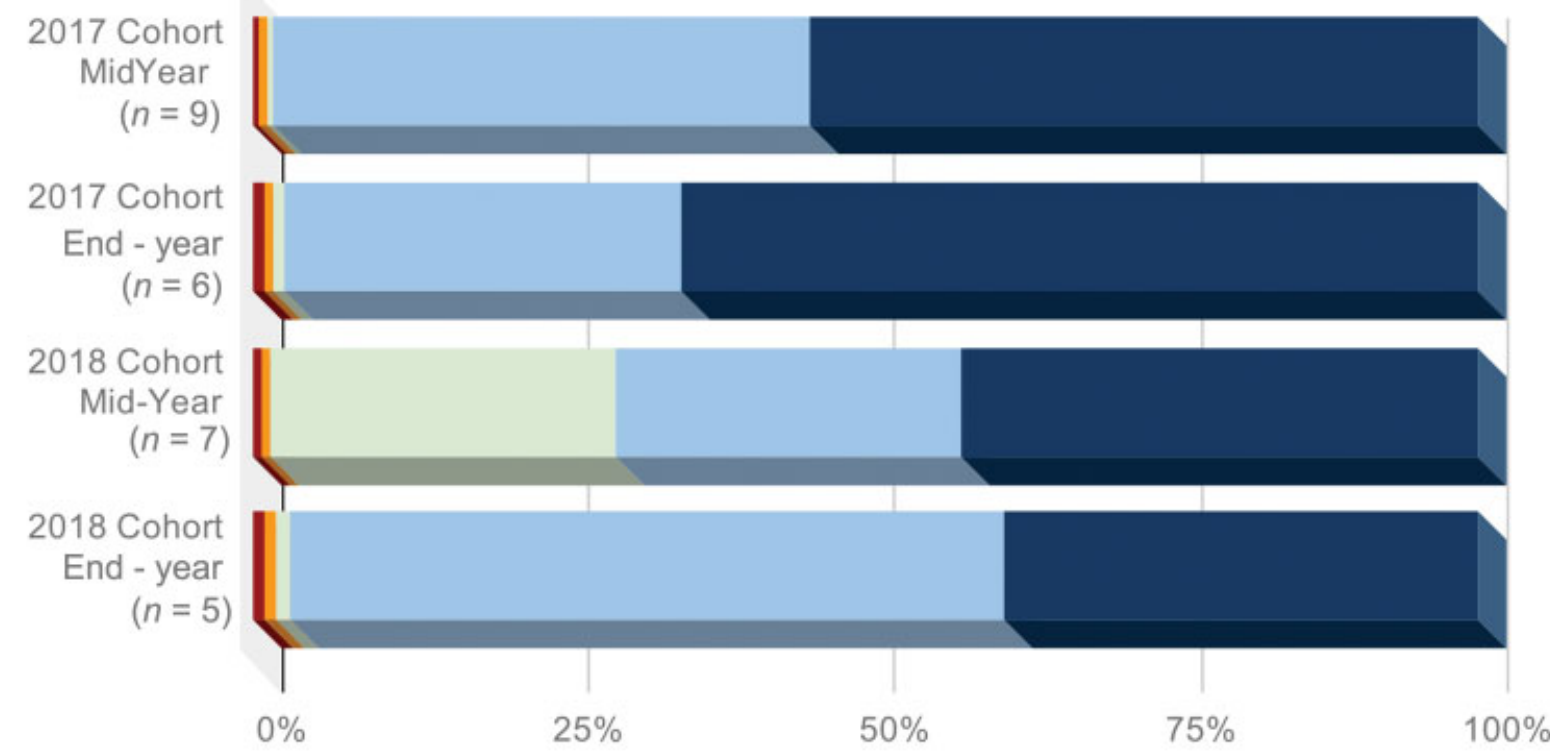

Fig. 1 Comparison of mentee satisfaction on a five-point scale ranging from "very unsatisfied" to "very satisfied" between the 2017 and 2018 cohorts at the midyear. 


\section{Mentee educational value}

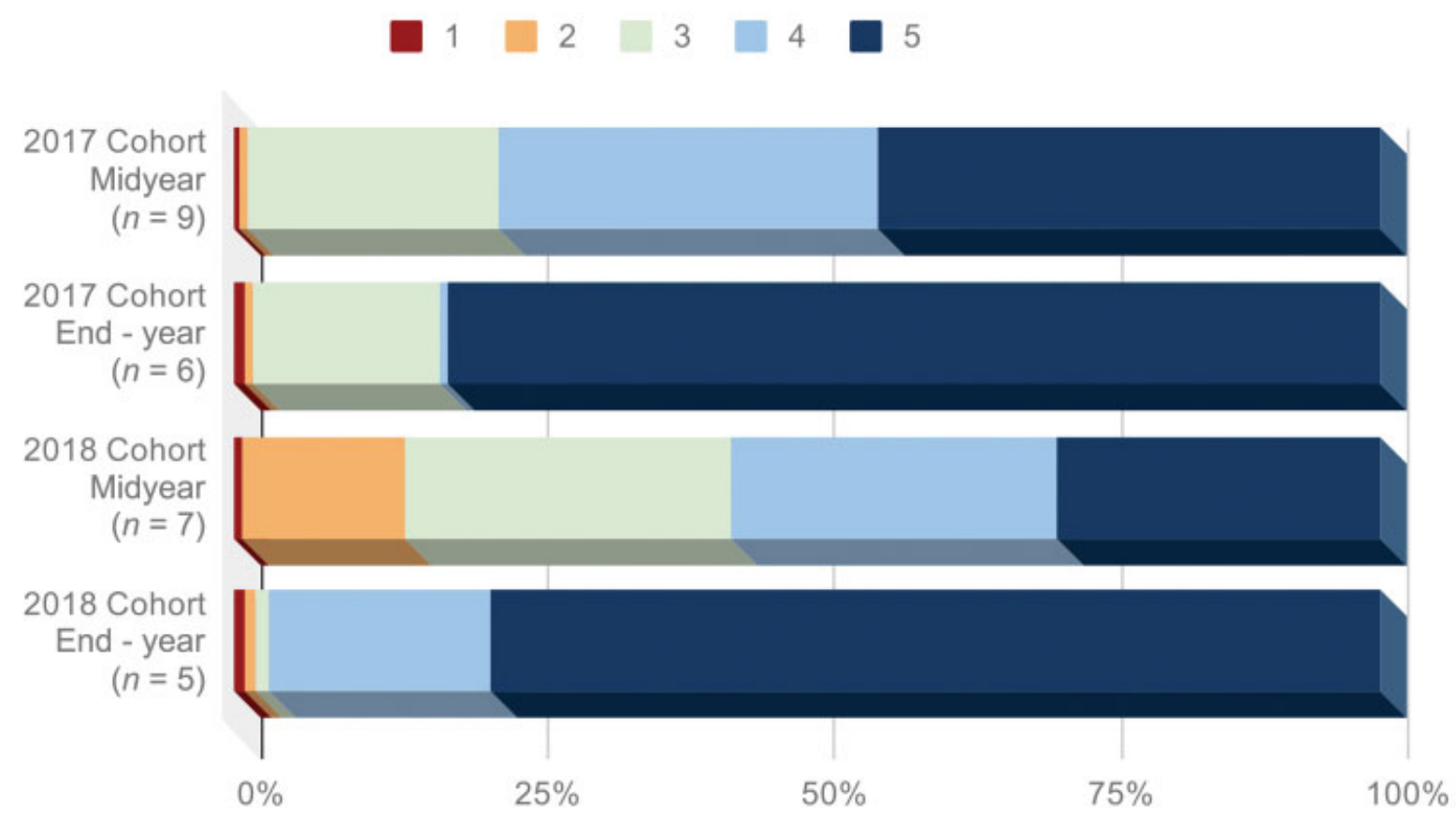

Fig. 2 Comparison of mentee educational value on a scale of 1 to 5 with increasing value between the 2017 and 2018 cohorts at the midyear.

\section{Mentor perceived quality of clinical experience with mentee}

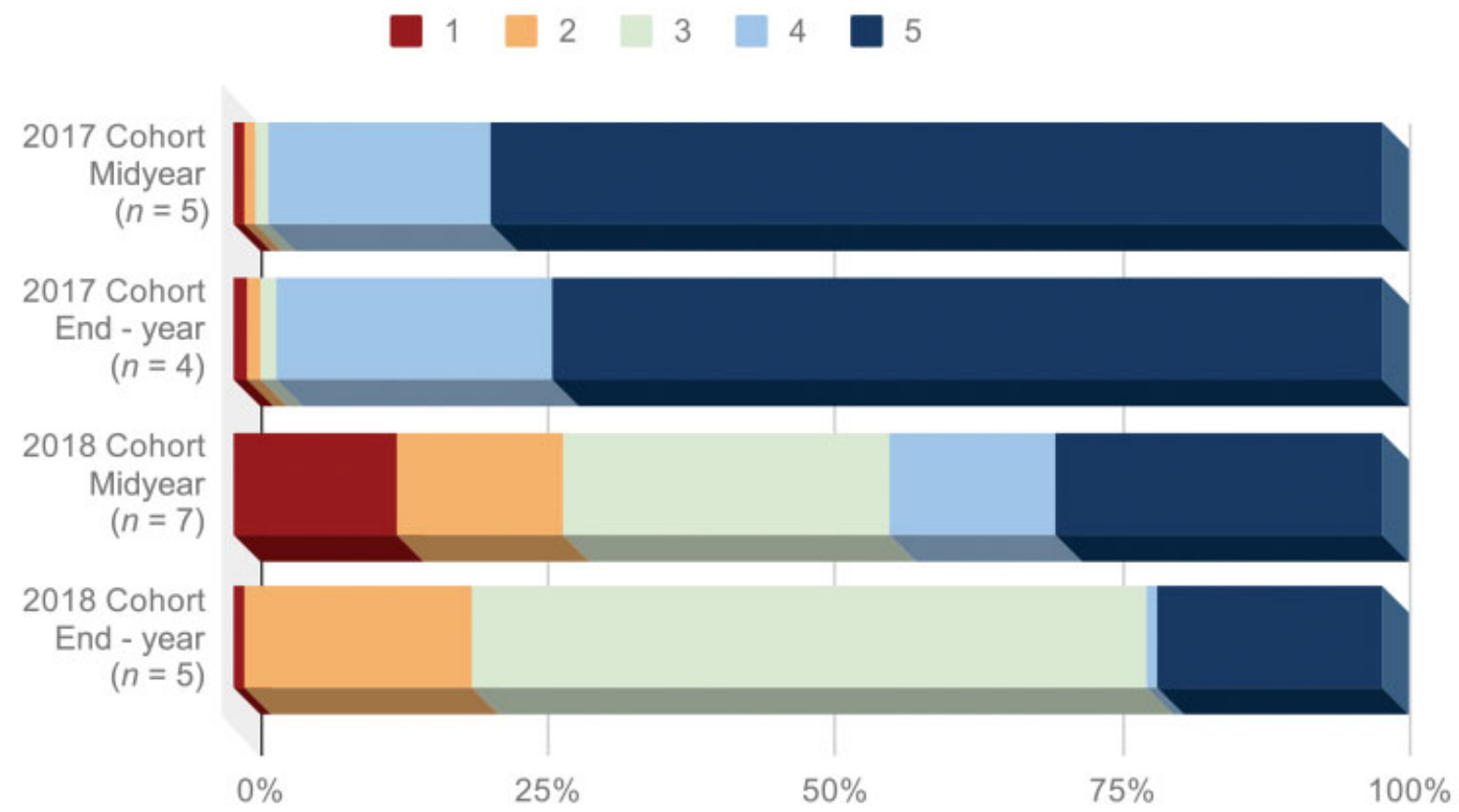

Fig. 3 Comparison of mentor perceived quality of clinical experience with mentee on a scale of 1 to 5 with increasing value between the 2017 and 2018 cohorts at the midyear.

completing their requirements. The reasons for such wide variation in response remain unclear and are likely multifactorial. Initial resident engagement and commitment to the program was identified as a major difference between the two cohorts. Feedback from the surveys highlights other possible contributing factors, including too many program requirements, stress from a rigorous medical school curriculum, and loss of communication between mentor and mentee for scheduling future shadowing experiences. Other considerations include a weak mentor-mentee relationship, lack of 
early interest in ophthalmology as a career choice, and class-toclass variation.

In response to the decrease in engagement and participation, MOP leadership discussed and implemented several program changes. The number of required clinical shadowing experiences was reduced from four to three per semester (one clinic shift, one call shift, one operating room [OR] shift) and the medical student clerkship coordinator began assisting with scheduling these experiences to reduce the burden on mentors and mentees. To help address the issue of stress endured during a busy basic science curriculum, senior leaders of the program proposed having regular office hours to provide students an outlet to discuss any areas of difficulty, as well as to offer advice for success, in both the classroom and clinical settings of medical school. With regard to building a stronger mentor-mentee relationship early on, additional social events shortly after the program's formal welcome have been added. Additional time is spent on growing this bond throughout the year with regular social events to increase student and resident investment in each other. Progress has already been noted from the changes we have been able to make, with 2018 yearend feedback being markedly more positive than at the midyear. Finally, to increase initial resident investment in the program, the committee plans to more formally introduce the program to incoming residents and develop a biannual mentoring workshop. This would not only emphasize the importance of the program's mission but also help to foster their life-long roles as mentors and leaders.

Despite the discrepancies between the first two cohorts of mentors and mentees, it is essential to acknowledge the success that this program has achieved so far, and to recognize the difficulty of its mission. Furthermore, it is important to realize that MOP is still in its very early stages, with significant room for improvement and growth. The outcome of a program seeking to increase URM presence in ophthalmology cannot be finally assessed until students complete their training and become practicing ophthalmologists. Nonetheless, the MOP leadership team remains optimistic that this pilot program will continue to attract interest from URM students each year, and that the new changes will result in participation and satisfaction levels comparable to those of our first cohort. Lastly, the team anticipates that the success of this program will incite the development of similar programs around the country aiming to address the important issue of diversity within ophthalmology, as well as other medical subspecialties.

Our "pipeline" program represents an ongoing effort to increase URM interest in ophthalmology. Despite early success, we continue to identify areas for growth and hope that MOP can provide a template for other programs initiating efforts to tackle this important issue.

\section{Funding}

None.
Conflict of Interest

None declared.

Acknowledgments

The authors thank Marshal Dial and VRmagic for their help with clinical simulations for mentees.

\section{References}

1 Saha S, Komaromy M, Koepsell TD, Bindman AB. Patient-physician racial concordance and the perceived quality and use of health care. Arch Intern Med 1999;159(09):997-1004

2 Xierali IM, Nivet MA, Wilson MR. Current and future status of diversity in ophthalmologist workforce. JAMA Ophthalmol 2016; 134(09):1016-1023

3 U.S. Census Bureau. (2011). Profile of general population and housing characteristics: 2010 demographic profile data. Available at: https://factfinder.census.gov/faces/tableservices/jsf/pages/productview.xhtml?src=bkmk. Accessed November 29, 2019

4 Deas D, Pisano ED, Mainous AG III, et al. Improving diversity through strategic planning: a 10-year (2002-2012) experience at theMedical University of South Carolina. Acad Med 2012;87(11): 1548-1555

5 Zhang X, Cotch MF, Ryskulova A, et al. Vision health disparities in the United States by race/ethnicity, education, and economic status: findings from two nationally representative surveys. Am J Ophthalmol 2012;154(6, Suppl):S53-62.e1

6 Walker KO, Moreno G, Grumbach K. The association among specialty, race, ethnicity, and practice location among California physicians in diverse specialties. J Natl Med Assoc 2012;104(1,2):46-52

7 Xierali IM, Castillo-Page L, Zhang K, Gampfer KR, Nivet MA. AM last page: the urgency of physician workforce diversity. Acad Med 2014;89(08):1192

8 Reede JY. A recurring theme: the need for minority physicians. Health Aff (Millwood) 2003;22(04):91-93

9 Simon AE, Marsteller JA, Lin SX. Physician-patient race concordance from the physician perspective. J Natl Med Assoc 2013;105 (02):150-156

10 National Eye Institute.: Vision problems in the U.S.: prevalence of adult vision impairment and age-related eye diseases in America. Available at: https://www.preventblindness.org/sites/default/files/ national/documents/VPUS_2008_update.pdf. Accessed November 29, 2019

11 Ross PT, et al. Doctors of tomorrow-a pipeline program for getting a head start in medicine. Int J Human Soc Sci Invent 2016;5(09): 33-37

12 Finks JF. Doctors of Tomorrow. Surgery at Michigan Medicine. Available at: https://medicine.umich.edu/dept/surgery/news/archive/201809/doctors-tomorrow. Accessed July 12, 2019

13 Oyesanya T, Grossberg AL, Okoye GA. Increasing minority representation in the dermatology department: the Johns Hopkins experience. JAMA Dermatol 2018;154(10):1133-1134

14 Plumridge S. Pipeline program fosters mentorship in medicine. Available at: news.feinberg.northwestern.edu/2015/01/urm-student-mentoring-mixer/. Accessed November 29, 2019

15 American Academy of Orthopaedic Surgeons. Rogers, Carolyn. AAOS Mentoring Program Wants YOU! www.aaos.org/AAOSNow/ 2007/Aug/youraaos/youraaos9/. Accessed November 29, 2019

16 American Academy of Ophthalmology. Minority ophthalmology mentoring. Available at: www.aao.org/minority-mentoring. Accessed November 29, 2019 


\section{Appendix}

Table 1 Complete survey questions

1. How valuable has this program and resident mentorship been to your educational development?

2. Overall, how would you rate the clinical experiences you've had with your mentee(s)?

3. Has this program increased your interest in ophthalmology as a potential career option?

4. Overall, how satisfied are you with the DEI ophthalmology mentorship program?

Table 2 Complete survey questions

1. How valuable has this program and resident mentorship been to your educational development?

2. My interest in ophthalmology has increased since starting the pipeline program.

3. My knowledge of ophthalmology has improved throughout the pipeline program.

4. My knowledge of DEl efforts within the field has improved throughout the Pipeline program.

5. I feel confident in my ability to apply clinical skills gained in the pipeline program.

Table 3 Complete survey questions

1. Overall, how would you rate the clinical experiences you've had with your mentee(s)?

2. I feel that I have grown significantly as an educator since participating in the Ophthalmology Pipeline Program.

3. I believe that my knowledge of efforts in Diversity, Health Equity, and Inclusion have increased since participating in the Ophthalmology Pipeline Program.

4. I believe that the pipeline program is an effective way to improve the presence of underrepresented minorities in ophthalmology. 